\title{
Effects of fluoride on proliferation and mineralization in periodontal ligament cells in vitro
}

\author{
K.Q. Li*, S.S. Jia*, M. Ma, H.Z. Shen, L. Xu, G.P. Liu, S.Y. Huang and D.S. Zhang \\ Department of Oral and Maxillofacial Surgery, Shandong Provincial Hospital Affiliated to Shandong University, Jinan, China
}

\begin{abstract}
Fluoride, which is often added to toothpaste or mouthwash in order to protect teeth from decay, may be a novel therapeutic approach for acceleration of periodontal regeneration. Therefore, we investigated the effects of fluoride on proliferation and mineralization in human periodontal ligament cells in vitro. The periodontal ligament cells were stimulated with various concentrations of $\mathrm{NaF}$ added into osteogenic inductive medium. Immunohistochemistry of cell identification, cell proliferation, alkaline phosphatase (ALP) activity assay, Alizarin red $S$ staining and quantitative real-time-polymerase chain reaction (RT-PCR) were performed. Moderate concentrations of NaF (50-500 $\mu \mathrm{mol} / \mathrm{L})$ had pro-proliferation effects, while $500 \mu \mathrm{mol} / \mathrm{L}$ had the best effects. ALP activity and calcium content were significantly enhanced by $10 \mu \mathrm{mol} / \mathrm{L} \mathrm{NaF}$ with osteogenic inductive medium. Quantitative RT-PCR data varied in genes as a result of different NaF concentrations and treatment periods. We conclude that moderate concentrations of $\mathrm{NaF}$ can stimulate proliferation and mineralization in periodontal ligament cells. These in vitro findings may provide a novel therapeutic approach for acceleration of periodontal regeneration by addition of suitable concentrations of $\mathrm{NaF}$ into the medication for periodontitis treatment, i.e., into periodontal packs and tissue patches.
\end{abstract}

Key words: Fluoride; Periodontitis; Periodontal ligament cells; Mineralization

\section{Introduction}

Fluoride is found in teeth, bones, thyroid gland and skin of humans. Since reports of its strengthening effect on bones and teeth at recommended doses, it is officially considered to be a beneficial element for humans. However, chronic excessive intake of fluoride in water, diet and dentifrices may result in fluoride poisoning, which manifests as enamel fluorosis and bone injuries (1). Fluorosis extraperiosteal calcification and ossification could be detected during the development of severe skeletal fluorosis (2). It is generally accepted that fluoride-induced extraperiosteal ossification is closely associated with fibroblasts. Fibroblasts have been classified as inducible-osteogenic precursor cells that have an osteogenic function under special conditions (3). According to a previous study, the osteogenic function of fibroblasts induced by fluoride could play an important role in the development of extraperiosteal ossification during skeletal fluorosis (4). The authors suggest that, induced by excessive fluoride, fibroblasts could be stimulated to express osteogenic phenotype, increase osteogenic activity, and result in extraperiosteal ossification of bone injuries $(2,4)$.

Periodontitis is a highly prevalent inflammatory oral disease. It can lead to the destruction of periodontal tissues and the loss of bone that surrounds the teeth. This disease is a major cause of adult tooth loss. Current treatments mainly aim at removing local stimulus and controlling inflammation. Afterwards, efforts are made to repair periodontal supporting tissues, which means achieving simultaneous regeneration of the lost alveolar bone, cementum and periodontal soft tissues. Unfortunately, in most cases, alveolar bone repair and regeneration following periodontitis treatment is still a challenge presented to dentists (5).

Periodontal tissues include alveolar bone, periodontal ligament, cementum and gums. The periodontal ligament is a specialized dense connective tissue embedded between the roots, cementum, and the alveolar bone. Early evidence shows that the periodontal ligament plays an important role in the maintenance of the periodontal tissue homeostasis by maintaining the balance between bone formation and resorption (6). It is composed of several different cell populations, such as fibroblasts, cementoblasts, osteoblasts, osteoclasts, and mesenchymal cells. Of all cells in the periodontal ligament, fibroblasts are the most numerous and of great importance in bone remodeling (7-9). Periodontal ligament fibroblasts are mesenchymal with intense contribution in periodontal ligament metabolism, collagen fibers synthesis, and metabolism of other constituent of the

Correspondence: D.S. Zhang: <ds63zhang@sdu.edu.cn>

${ }^{*}$ These authors contributed equally to this study.

Received February 4, 2016 | Accepted April 29, 2016 
extracellular matrix (10). In vitro studies of cultured periodontal ligament fragments, periodontal ligament cells (PDLCs) are described as fiber-cord-like cells. They are reported as having multi-differentiation potential, being able to differentiate into fibroblasts, osteoblasts, and bone forming cells. Much of the research in recent years has confirmed that PDLCs can form bone nodules and express bone-related proteins, such as alkaline phosphatase (ALP), bone sialoprotein (BSP) and osteocalcin (OCN) under certain circumstances (11-14).

However, the majority of the studies investigating the effects of fluoride on osteogenic differentiation have used either osteoblasts or osteosarcoma cell lines, and currently no knowledge exists about the response of human PDLCs to fluoride. The primary objective of this study was to investigate the effects of fluoride on proliferation and mineralization in human PDLCs in vitro.

\section{Material and Methods}

\section{Cell culture}

PDLCs were obtained from healthy premolar or third molar teeth extracted from patients ( 11 to 23 years of age) for orthodontic treatment or preventive procedures. Teeth were placed in a minimum essential medium (a-MEM; Hyclone, USA), containing $20 \%$ fetal bovine serum (FBS; Biological Industries, USA), $100 \mathrm{U} / \mathrm{mL}$ of penicillin, and $100 \mathrm{mg} / \mathrm{mL}$ of streptomycin (Gibco, USA). Teeth were then washed with sterile phosphate-buffered saline (PBS) containing $100 \mathrm{U} / \mathrm{mL}$ of penicillin, and $100 \mathrm{mg} / \mathrm{mL}$ of streptomycin as many times as possible until all blood and bone fragments were rinsed away. Single-use sterile scalpel was used to carefully scrap the periodontal ligament tissue from the middle third of the root surface. Tissue was centrifuged at $190 \mathrm{~g}$ at room temperature for $5 \mathrm{~min}$. Digestion of collected tissue was done with $3 \mathrm{mg} / \mathrm{mL}$ of collagenase type I and $4 \mathrm{mg} / \mathrm{mL}$ of dispase (Sigma-Aldrich, USA) for $15 \mathrm{~min}$ with shaking every $5 \mathrm{~min}$ in constant temperature in $37^{\circ} \mathrm{C}$ water bath. After terminating digestion, centrifugation described as before was again performed. The supernatant was removed and the precipitate collected, pooled and plated into a $12.5-\mathrm{cm}^{2}$ cell culture flask (Corning, USA) with $2 \mathrm{~mL}$ complete a-MEM medium. The flask was placed vertically into a humidified incubator with $37^{\circ} \mathrm{C}$ constant temperature, $95 \%$ air, $5 \% \mathrm{CO}_{2}$ for $4 \mathrm{~h}$; it was then placed horizontally. Medium was replaced every 3 days until cell growth of $70-80 \%$ confluency. Digestion and passage was done with $0.25 \%$ trypsin protease (Gibco). Then cells were again incubated with complete a-MEM medium with $10 \% \mathrm{FBS}, 100 \mathrm{U} / \mathrm{mL}$ of penicillin, and $100 \mathrm{mg} / \mathrm{mL}$ of streptomycin. Cultures between passage 3 and 6 were used in the experiments.

\section{Immunohistochemistry}

First, the cells were attached to cell slides at a density of $5 \times 10^{4}$ cells per well in 24-well plates (Eppendorf,
Germany) with complete culture medium. After $48 \mathrm{~h}$, the cell slides were gently rinsed with PBS three times and fixed with $4 \%$ paraformaldehyde (PFA; Boster, China) for $20 \mathrm{~min}$. Finally, the chromogenic reaction was performed with a diaminobenzidine kit (Beijing Zhongshan Golden Bridge Biotechnology, China). The cell slides were incubated with primary antibodies against vimentin and cytokeratins (Beijing Zhongshan Golden Bridge Biotechnology) at a dilution of $1: 50$ for $18 \mathrm{~h}$ at $4^{\circ} \mathrm{C}$. At the same time, PBS was used as a substitute for the primary antibodies as a negative control.

\section{CCK-8 assay}

Effects of various concentrations of $\mathrm{NaF}$ (Sigma, USA) on PDLCs proliferation was measured using a cell counting kit (CCK-8; Beyotime, China). PDLCs were seeded into 96-well culture plates (Eppendorf) with a concentration of $1 \times 10^{3}$ cells/well. After $24-h$ incubation at $37^{\circ} \mathrm{C}$ with $5 \% \mathrm{CO}_{2}$, the plates were treated with $0,1,5,10$, $50,100,5 \times 10^{2}, 1 \times 10^{3}$, and $5 \times 10^{3} \mu \mathrm{mol} / \mathrm{L} \mathrm{NaF}$ for 1,2 , $3,4,5$, and 6 days. CCK-8 was mixed with serum-free a-MEM medium at a proportion of 1:10 in advance. After removal of complete a-MEM medium, $110 \mu \mathrm{L}$ mixture was added to each well and incubated at $37^{\circ} \mathrm{C}$ for $2 \mathrm{~h}$, until the media turned yellow. Groups without cells were used as zero setting. We assessed cell viability by absorbance values in each well, which was measured with a spectrophotometer (Thermo, Finland) at a wavelength of $450 \mathrm{~nm}$. Data were calculated using averages of three wells, and untreated PDLCs were considered as the control group. The concentrations of $0,10,5 \times 10^{2}$ and $1 \times 10^{3} \mu \mathrm{mol} / \mathrm{L}$ were chosen for subsequent experiments.

\section{NaF treatment}

$\mathrm{NaF}$ was added to osteogenic inductive culture medium. There were four treatment groups: 1) osteogenic medium (basic culture medium supplemented with $10 \mathrm{mM}$ / $\mathrm{L}$ beta-glycerophosphate, $0.1 \mu \mathrm{m} / \mathrm{L}$ dexamethasone, and $50 \mu \mathrm{g} / \mathrm{L}$ L-ascorbic acid; all from Sigma), 2) osteogenic medium supplemented with $10 \mu \mathrm{mol} / \mathrm{L} \mathrm{NaF}, 3)$ osteogenic medium supplemented with $5 \times 10^{2} \mu \mathrm{mol} / \mathrm{L} \mathrm{NaF}$, and 4) osteogenic medium supplemented with $1 \times 10^{3} \mu \mathrm{mol} / \mathrm{L}$ NaF. The PDLCs were treated the same way in subsequent experiments. The medium was replaced every 3 days.

\section{ALP activity assay}

PDLCs were plated at a density of $1 \times 10^{4}$ cells/well in 24-well culture plates (Eppendorf) and cultured in basal medium. When cells reached $70-80 \%$ confluency, plates were treated with different concentrations of NaF. For ALP staining, cells triggered for 14 days were washed three times with PBS and fixed with 4\% PFA for 20 min at room temperature. The fixed cells were stained with a BCIP/ NBT ALP Color Development Kit (Leagene, China). Double-distilled water was added to each well to stop 
Table 1. Specific primer sequences used for RT-PCR analysis.

\begin{tabular}{lcl}
\hline Genes & Product size $(\mathrm{bp})$ & \multicolumn{1}{c}{ Sequences } \\
\hline Runx2 & 136 & $\mathrm{~F}\left(5^{\prime}-3^{\prime}\right):$ TCCACACCATTAGGGACCATC \\
& & $\mathrm{R}\left(5^{\prime}-3^{\prime}\right):$ TGCTAATGCTTCGTGTTTCCA \\
COL1A1 & 198 & $\mathrm{~F}\left(5^{\prime}-3^{\prime}\right):$ GCTTGGTCCACTTGCTTGAAGA \\
& $\mathrm{R}\left(5^{\prime}-3^{\prime}\right):$ GAGCATTGCCTTTGATTGCTG \\
ALP & 141 & $\mathrm{~F}\left(5^{\prime}-3^{\prime}\right):$ CATGCTGAGTGACACAGACAAGAA \\
& & $\mathrm{R}\left(5^{\prime}-3^{\prime}\right):$ ACAGCAGACTGCGCCTGGTA \\
OCN & 111 & $\mathrm{~F}\left(5^{\prime}-3^{\prime}\right):$ CCCAGGCGCACCTGTATCAA \\
& & $\mathrm{R}\left(5^{\prime}-3^{\prime}\right):$ GGTCAGCCAACTCGTCACAGTC \\
GAPDH & 138 & $\mathrm{~F}\left(5^{\prime}-3^{\prime}\right):$ GCACCGTCAAGGCTGAGAAC \\
& & $\mathrm{R}\left(5^{\prime}-3^{\prime}\right):$ TGGTGAAGACGCCAGTGGA \\
\hline
\end{tabular}

RT-PCR: reverse transcription-polymerase chain reaction; bp: base pairs; Runx2: Runtrelated transcription factor2; COL1A1: type I collagen- $\alpha$; ALP: alkaline phosphatase; OCN: Osteocalcin; GAPDH: glyceraldehyde 3-phosphate dehydrogenase; F: forward; $\mathrm{R}$ : reverse.

reaction after $30 \mathrm{~min}$. The BCIP/NBT method produced an insoluble blue NBT formazan. ALP stained areas were measured quantitatively with Image-Pro Plus 6.0 (Media Cybernetics, USA).

\section{Quantitative real-time polymerase chain reaction (RT-PCR)}

After reaching $70-80 \%$ confluency from PDLCs seeded in 6 -well plates at a density of $1 \times 10^{5}$ cells/well, different concentrations of $\mathrm{NaF}$ were added as previously described for 7, 14, and 21 days. After treatments, the cells were lysed using RNAisoTM Plus (TakaRa, China) to isolate total RNAs. Single-stranded complementary DNA (cDNA) was obtained by reverse transcribing $1 \mu \mathrm{g}$ of total RNA from each sample using PrimeScript ${ }^{B}$ RT reagent kit (TakaRa). Quantitative RT-PCR of Runt-related transcription factor 2 (Runx2), type I collagen $\alpha 1$ (COL1A1), ALP, OCN and glyceraldehyde 3phosphate dehydrogenase (GAPDH) were performed on an equal amount of CDNA using SYBR ${ }^{B}$ Premix Ex TaqTM ॥ (TakaRa) according to the manufacturer's instructions. Reactions were performed in triplicate on LightCycler ${ }^{(B)} 480$ System Real-Time PCR (Roche, Switzerland). The cycling parameters used were: $95^{\circ} \mathrm{C}$ for $30 \mathrm{~s}$, followed by 40 cycles of $95^{\circ} \mathrm{C}$ for $5 \mathrm{~s}, 60^{\circ} \mathrm{C}$ for $30 \mathrm{~s}$, and $72^{\circ} \mathrm{C}$ for $30 \mathrm{~s}$, and a dissociation program of $95^{\circ} \mathrm{C}$ for $15 \mathrm{~s}, 60^{\circ} \mathrm{C}$ for $30 \mathrm{~s}$, and $95^{\circ}$ $\mathrm{C}$ for $15 \mathrm{~s}$. Melting curve analysis was included to assure that only one PCR product was formed. Expression of housekeeping gene GAPDH was amplified as an internal control. The relative amount of RNA was calculated by the $2^{-\Delta \Delta C t}$ method. Primer and probe sequences for Runx2, COL1A1, ALP, and OCN, and GAPDH are shown in Table 1.

\section{Alizarin red $\mathbf{S}$ staining}

PDLCs were subcultured in 24-well culture plates similarly to the ALP activity assay. Mineralization at 28 days was assessed by Alizarin red S staining, which stains the calcium minerals red. Cells were fixed in 4\% PFA for $20 \mathrm{~min}$ and then stained with $2 \%$ Alizarin red S (pH 8.3; Leagene) solution with $500 \mu \mathrm{L} /$ well for $30 \mathrm{~min}$ at room temperature. The excess dye was washed away with double-distilled water. After photographing, semi-quantitative measurement of mineralization was taken. The Alizarin red S-stained cultures were incubated with $500 \mu \mathrm{L} 10 \%$ cetylpyridinium chloride (CTC; Meilun, China) for $15 \mathrm{~min}$ to solubilize and release calcium-bound Alizarin red into solution. The absorbance of the released Alizarin red $\mathrm{S}$ was measured at $562 \mathrm{~nm}$ in 96-well plates using a spectrophotometer. Groups of CTC were used as zero setting.

\section{Statistical analysis}

Data are reported as mean $\pm S D$ from at least three independent experiments. Data were analyzed by one-way analysis of variance (ANOVA) using SPSS software (SPSS Inc., USA). $P$ values less than 0.05 were considered to be statistically significant.

\section{Results}

\section{Cell culture and identification}

In the course of primary cultured periodontal ligament cells, inverted microscope was used for observation of cell morphology and growth. After 7 to 10 days, adherent cells could be found radially stretching out from the edge of periodontal ligament fragments (Figure 1A). When approaching $70-80 \%$ confluency, fiber-cord-like cells kept growing vigorously (Figure 1B). Positive staining was observed for vimentin in the cytoplasm (Figure 1C), while staining was negative for cytokeratin (Figure 1D). Immunohistochemistry indicated that the cultured cells originated 

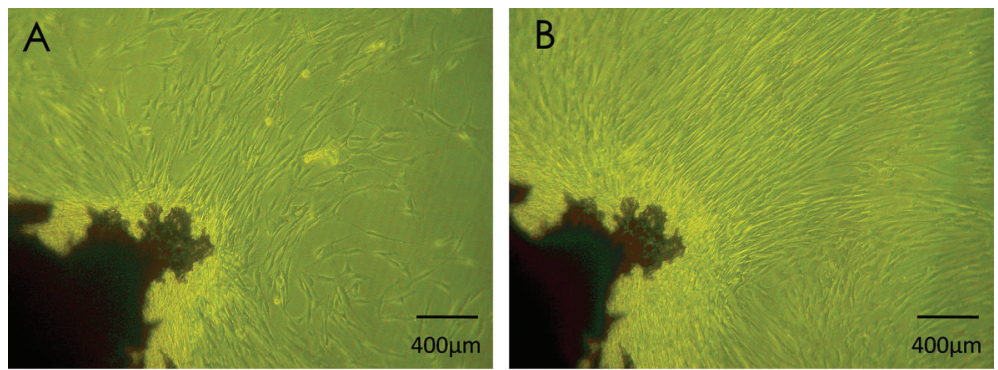

Figure 1. Periodontal ligament cell cultures and identification. $A$, primary cells shaped like fibroblasts and stretched radially from the tissue after $7-10$ days. $B$, fiber-cord-like cells kept growing vigorously and reached $70-80 \%$ confluency after 10-14 days. $C$, immune histological staining was positive for vimentin. $D$, immune histological staining was negative for cytokeratin (all $100 \times$ ).
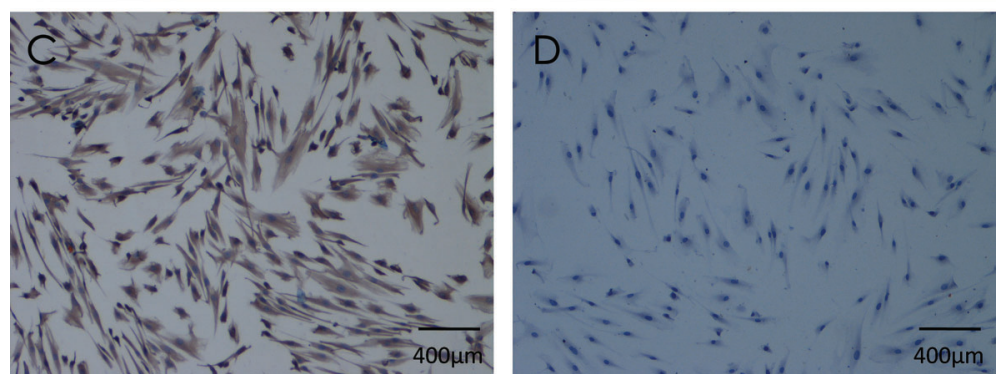

from mesenchyme and not from epithelium, information that can be used reliably in further experiments.

\section{Dose effects of fluoride on cell proliferation}

To study the effect of the various concentrations of $\mathrm{NaF}$ on PDLCs proliferation, we determined cell viability by CCK-8 assay after 1, 2, 3, 4, 5 and 6 days of culture. As shown in Figure $2 \mathrm{~A}$, there were no significant differences between the $\mathrm{NaF}$ concentrations and the control at days 1 , 2 and $3(P>0.05)$. On the contrary, from day 5 onwards, absorbance was significantly increased by the 50,100 , $5 \times 10^{2} \mu \mathrm{mol} / \mathrm{L}$ treatments compared to the control, while $5 \times 10^{2} \mu \mathrm{mol} / \mathrm{L} \mathrm{NaF}$ caused the highest value at day 6 as shown in Figure 2B. However, when the concentration increased up to $5 \times 10^{3} \mu \mathrm{mol} / \mathrm{L}$, the absorbance exhibited a significant decrease compared to the control group $(P<0.05)$, indicating a cytotoxic effect. These data indicate that $\mathrm{NaF}$ has dose-dependent effects on cell proliferation.

\section{ALP activity assay}

As demonstrated in Figure 3, the ALP activity at day 14 was significantly promoted by the 10 and $5 \times 10^{2} \mu \mathrm{mol} / \mathrm{L}$ treatment compared to the control, while $10 \mu \mathrm{mol} / \mathrm{L} \mathrm{NaF}$ caused the highest ALP positive area $(P<0.05)$. However, no significant differences were found between $1 \times 10^{3} \mu \mathrm{mol} /$ L-NaF-treated and untreated groups at the same time point $(P>0.05)$. This suggests that supplementing with a moderate concentration of $\mathrm{NaF}$ could induce further mineralization of PDLCs in the presence of osteogenic inducers.

\section{Quantitative real-time polymerase chain reaction (RT-PCR)}

The gene expression of osteogenic marker genes Runx2, COL1A1, ALP, OCN and GAPDH was studied at time points 7, 14 and 21 days for the purpose of further analysis of the osteogenic differentiation of PDLCs in response to the NaF treatment. As seen in Figure 4A,
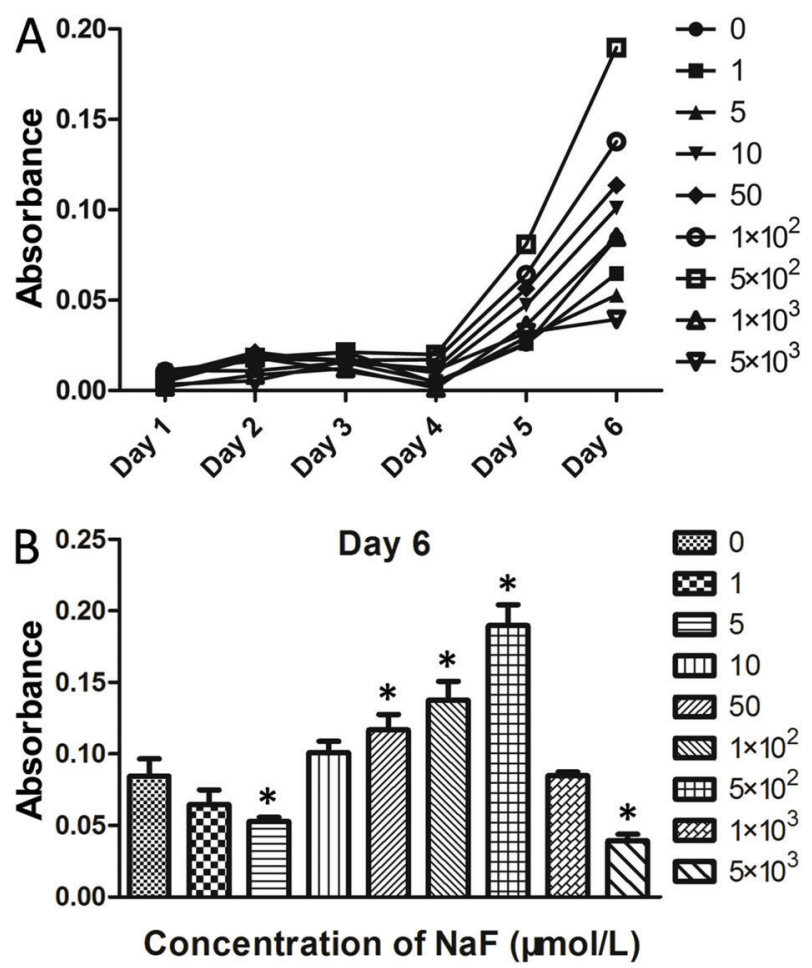

Figure 2. Effects of various concentrations of $\mathrm{NaF}$ ( $\mu \mathrm{mol} / \mathrm{L}$ ) on cell proliferation of periodontal ligament cells. $A$, cell proliferation from days 1 to 6 . $B$, cell proliferation at day 6 . Data are reported as means $\pm S D$. ${ }^{*} P<0.05$ compared to the control group (ANOVA). 


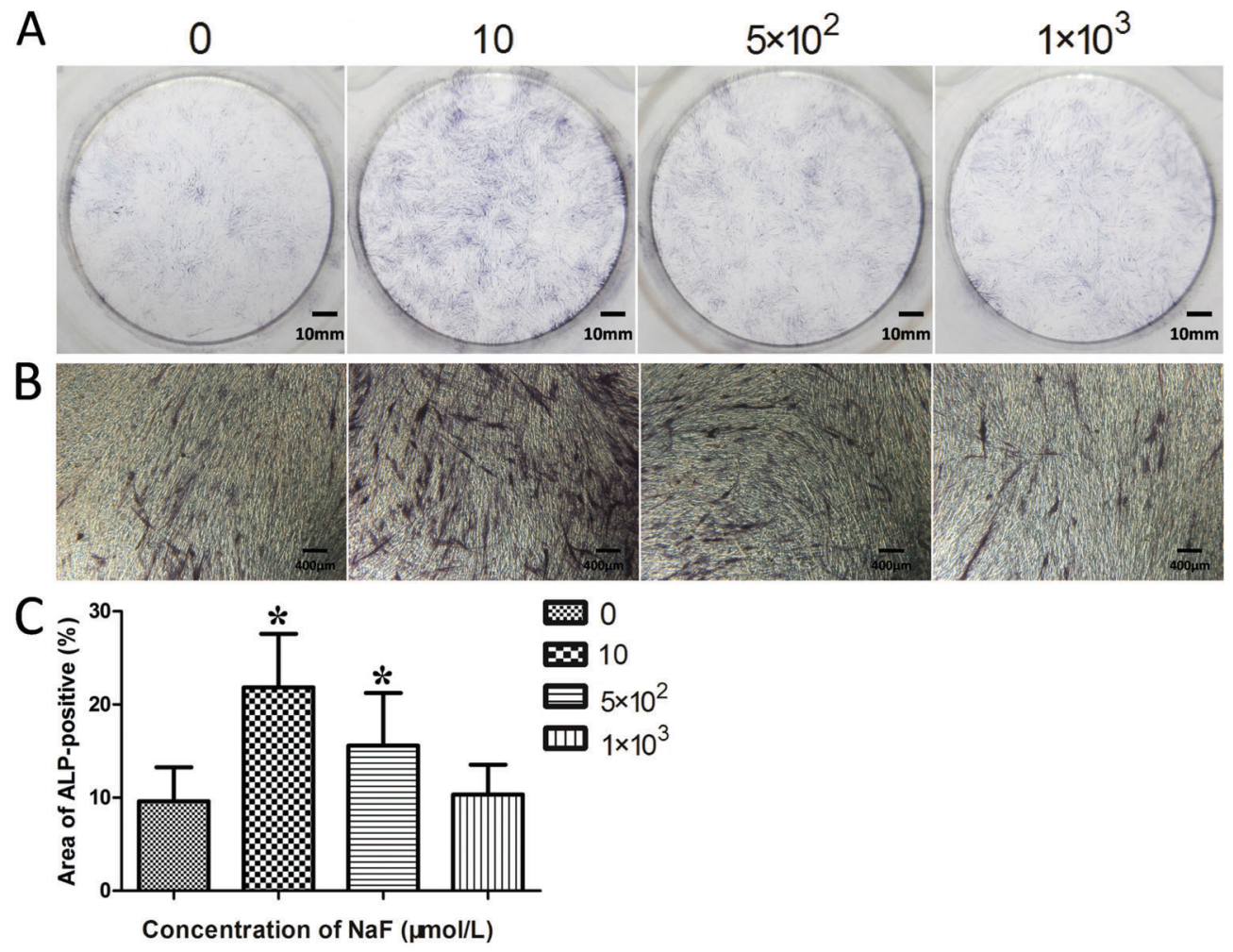

Figure 3. Effects of various concentrations of $\mathrm{NaF}(\mu \mathrm{mol} / \mathrm{L})$ on the alkaline phosphatase (ALP) activity of periodontal ligament cells. $A$, ALP staining after 14 days. $B$, ALP staining after 14 days $(100 \times)$. C, ALP positive areas collected by Image-Pro Plus 6.0 on day 14 . Data are reported as means $\pm S D$. ${ }^{*} P<0.05$ compared to the control group (ANOVA).

$5 \times 10^{2} \mu \mathrm{mol} / \mathrm{L} \mathrm{NaF}$ significantly increased expression of Runx2 at 7 days. In Figure 4B, the mRNA expression level of COL1A1 showed a significantly downward trend along with $5 \times 10^{2} \mu \mathrm{mol} / \mathrm{L} \mathrm{NaF}$ added for the first 7 and 14 days $(P<0.05)$. However, as the culture time increased, COL1A1 mRNA expression was significantly increased on day $21(P<0.05)$. ALP expression also showed the same change trend following $5 \times 10^{2} \mu \mathrm{mol} / \mathrm{L} \mathrm{NaF}$ addition (Figure 4C). Moreover, $10 \mu \mathrm{mol} / \mathrm{L} \mathrm{NaF}$ increased ALP mRNA level at both 7 and 14 days $(P<0.05)$. The increase of OCN mRNA expression level occurred at day 14 with $1 \times 10^{3} \mu \mathrm{mol} / \mathrm{L} \mathrm{NaF}(P<0.05)$ (Figure 4D). These data indicated that the exposure of fluoride for a certain period may influence cell differentiation.

\section{Alizarin red $\mathbf{S}$ staining}

After 28 days of culture, the calcium content in the cultures was measured. The calcium content in the $10 \mu \mathrm{mol} /$ L-NaF-treated group was higher than the control group $(P>0.05)$. However, in the $5 \times 10^{2}$ and $1 \times 10^{3} \mu \mathrm{mol} / \mathrm{L}$ groups there was a significant reduction of the calcium content $(P<0.05$; Figure 5). This implied that mineralized matrix deposition gradually increased with $10 \mu \mathrm{mol} / \mathrm{L} \mathrm{NaF}$ in the presence of osteogenic inducers. The addition of $5 \times 10^{2}$ and $1 \times 10^{3} \mu \mathrm{mol} / \mathrm{L} \mathrm{NaF}$ resulted in reduced calcium deposition at day 28.

\section{Discussion}

Much work has been done to study the dual effect of fluoride on bone formation. Although chronic excessive fluoride intake can result in skeletal fluorosis, low concentrations of fluoride are normally used to reduce the incidence of caries. In recent years, several investigations have suggested that fluoride could promote osteoblastic differentiation (4,15-18). PDLCs play an important role not only in the maintenance of periodontal ligament but also in the promotion of periodontal regeneration (19). Previous reports showed that PDLCs have great potential for osteogenic differentiation (11-14,20). However, effects of fluoride on proliferation and mineralization in human PDLCs in vitro have not been investigated. In this study, various concentrations of $\mathrm{NaF}$ were applied to PDLCs cultured in osteoinductive medium, and the results showed that fluoride could stimulate proliferation and mineralization in vitro. 

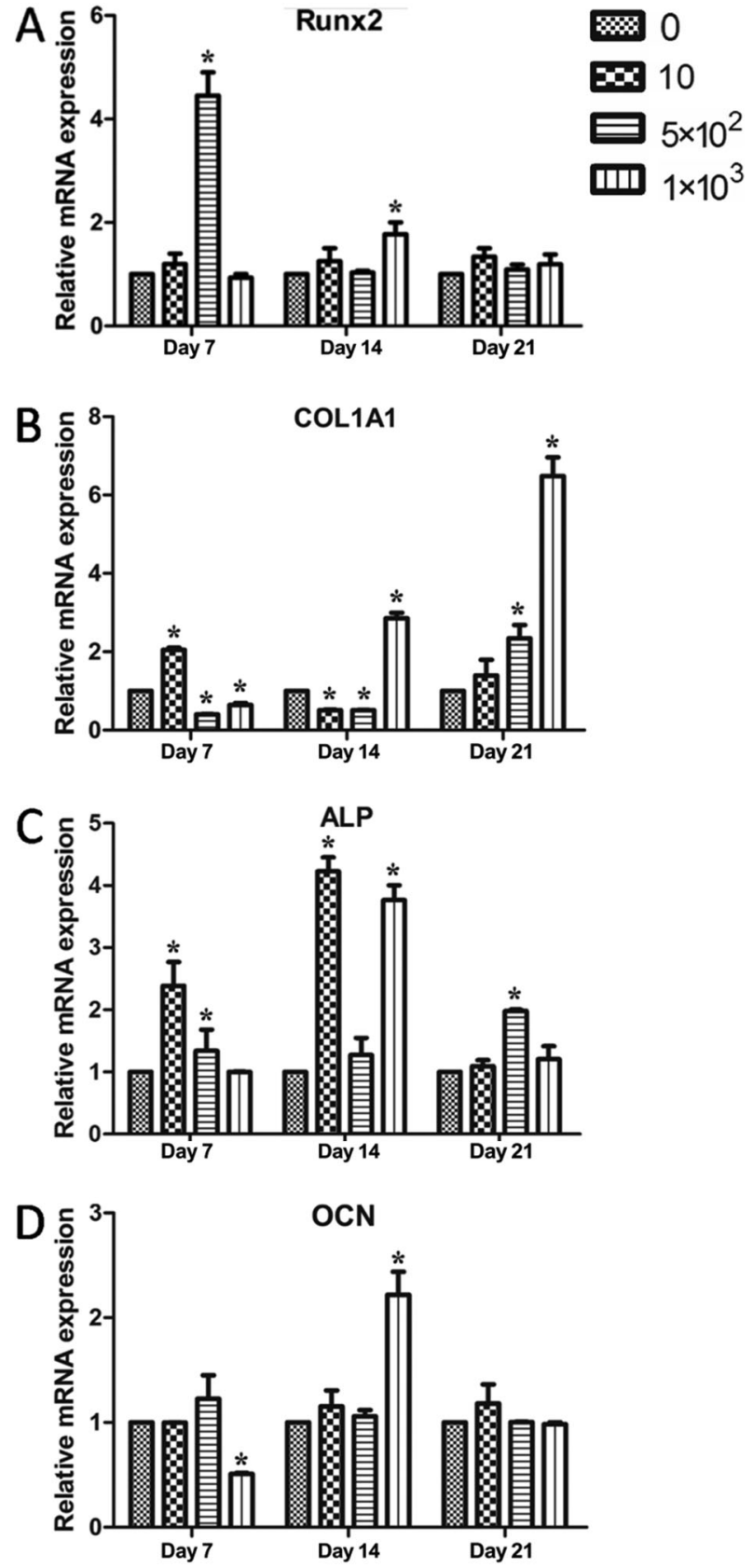

Figure 4. Effects of various concentrations of $\mathrm{NaF}(\mu \mathrm{mol} / \mathrm{L}$ ) on the osteogenic differentiation markers of periodontal ligament cells with quantitative RT-PCR analysis. The results are standardized to the reference gene GAPDH, and reported as relative mRNA levels. $A$, Runx2 mRNA. $B$, type I collagen $\alpha 1$ (COL1A1) mRNA. $C$, alkaline phosphatase (ALP) mRNA. D, Osteocalcin (OCN) mRNA. Data are reported as means $\pm S D$. ${ }^{*} P<0.05$ compared to the control group (ANOVA).

The CCK-8 assay is a convenient and efficient approach for assessment of cell viability, which was used to measure the effects of $\mathrm{NaF}$ on proliferation in PDLCs. Our study indicates that $\mathrm{NaF}$ has dose-dependent effects on cell proliferation. Cell viability increased from $50 \mu \mathrm{mol} / \mathrm{L}$ concentration of $\mathrm{NaF}$ and reached a peak at $5 \times 10^{2} \mu \mathrm{mol} / \mathrm{L}$. At a higher $\mathrm{NaF}$ concentration of $5 \times 10^{3} \mu \mathrm{mol} / \mathrm{L}$, the cell viability declined compared with control group. Our results are similar to those of a human osteosarcoma MG-63 cells in vitro investigation, which demonstrated that a moderate concentration up to $5 \times 10^{2} \mu \mathrm{mol} / \mathrm{L}$ of $\mathrm{NaF}$ has a pro-proliferation effect, while $2 \times 10^{3} \mu \mathrm{mol} / \mathrm{L} \mathrm{NaF}$ inhibited cell proliferation (15). According to another study examining the cellular mechanisms underlying the cytotoxicity induced by $\mathrm{NaF}$, concentrations higher than $5 \times 10^{3} \mu \mathrm{mol} / \mathrm{L}$ reduced the cell viability of human gingival fibroblasts (21). In a research of age-related changes of normal human oral cells sensitivity to $\mathrm{NaF}, \mathrm{NaF}$ dose-dependently reduced the viable cell number. However, no beneficial (growth promoting) effect (the so-called "hormesis") was seen in any of the three normal human oral cell types (pulp cell, gingival fibroblast, periodontal ligament fibroblast), except for those cells at the terminal phase, indicating that cells became resistant to cytotoxicity induced by $\mathrm{NaF}$ with aging (22). We may confirm that the effect of $\mathrm{NaF}$ on cell proliferation is concentration-, time- and cell-type-dependent.

As described before, after supplementation with moderate concentrations of fluoride, a growth of PDLCs was stimulated. However, in order to identify a suitable concentration of $\mathrm{NaF}$ for novel therapeutic approaches for acceleration of periodontal regeneration, our experiment tested fluoride concentrations of $10,5 \times 10^{2}$ and $1 \times 10^{3} \mu \mathrm{mol} / \mathrm{L}$ (low, medium, and high-dose $\mathrm{NaF}$ ) on the premise that there was no cytotoxicity on PDLCs during the pilot period.

As known, ALP is an early well-defined marker of osteogenic differentiation, and higher ALP activity represents a greater potential for bone formation. In this investigation, we assessed effects of various concentrations of NaF on ALP activity of PDLCs. Previous studies indicate that the addition of fluoride could affect ALP activity in other cells with a potential for bone forming. Human bone marrow mesenchymal stem cells grown on fluoride-modified titanium implant specimens showed higher ALP activity compared with grit-blasted ones (23). In primary rat osteoblasts, concentrations from 0.1 up to $100 \mu \mathrm{mol} / \mathrm{L} \mathrm{NaF}$ can significantly promote ALP activity compared with an untreated group (16). In agreement with that report, the present results showed that cells treated with 10 and $5 \times 10^{2} \mu \mathrm{mol} / \mathrm{L} \mathrm{NaF}$ showed a significant increase in ALP activity.

This study investigated the widely used bone formation markers Runx2, ALP, COL1A1 and OCN by RT-PCR against the housekeeping gene, GAPDH (16-18). PDLCs under differentiation could synthesize different products in different stages. Runx2 is an important transcription factor that plays a central role in bone formation (24). The expression of COL1A1, as well as of ALP, represents early osteogenic differentiation. Transcription of COL1A1 and OCN can be 


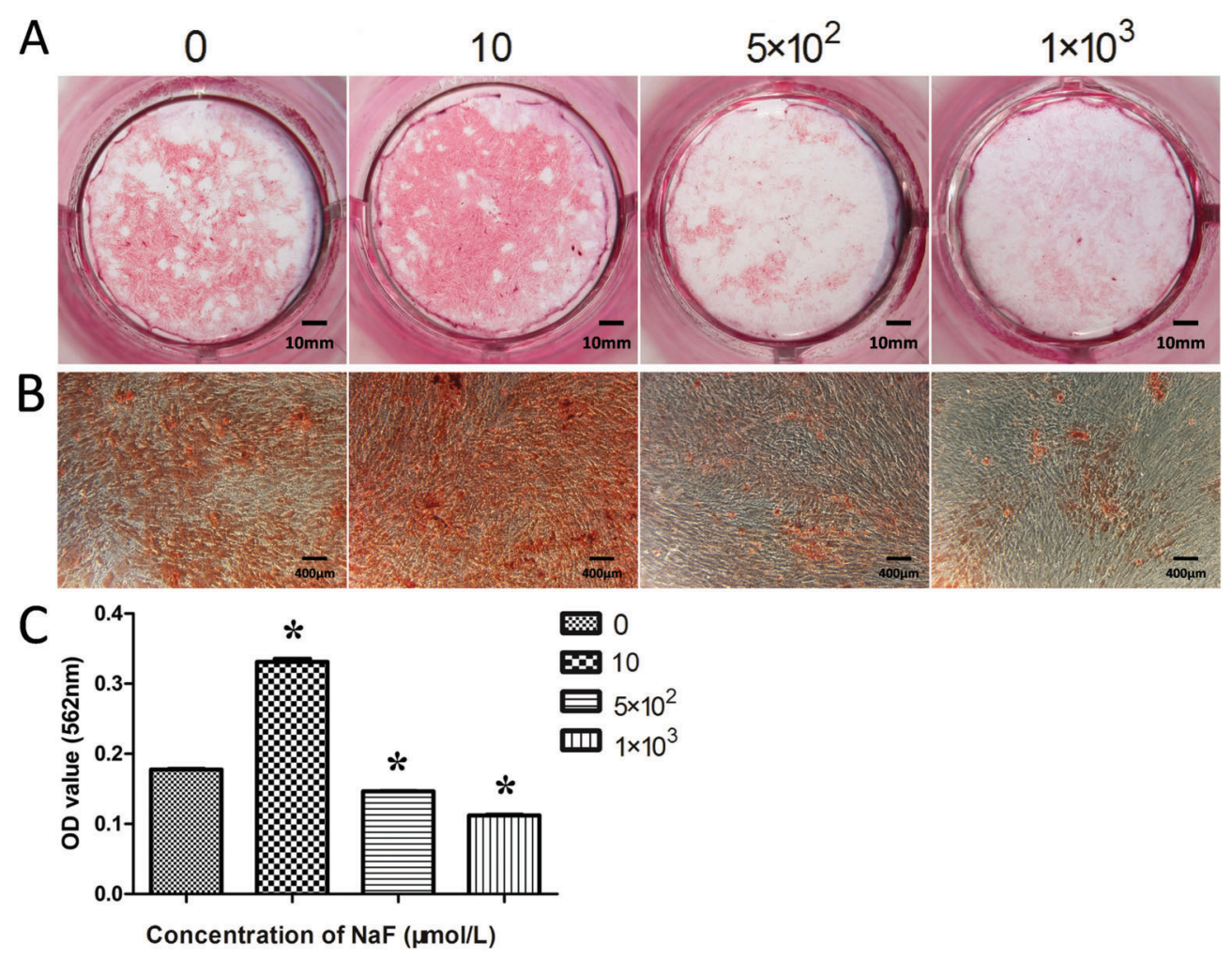

Figure 5. Effects of various concentrations of $\mathrm{NaF}$ on the calcified nodules formation of periodontal ligament cells. A, cultured PDLCs formed calcified nodules that stained positively for Alizarin red S staining after 28 days. B, Alizarin red S staining after 28 days (100 $\times$ ). $C$, Quantitative comparison of mineralized nodule formation among the groups. Data are reported as means $\pm S D$. ${ }^{*} P<0.05$ compared to the control group (ANOVA).

directly stimulated by Runx2 $(25,26)$. In the present study, $5 \times 10^{2} \mu \mathrm{mol} / \mathrm{L} \mathrm{NaF}$ increased expression of Runx2 as well as proliferation. As the culture time increased, $1 \times 10^{3} \mu \mathrm{mol} / \mathrm{L}$ NaF promoted COL1A1 mRNA expression. $10 \mu \mathrm{mol} / \mathrm{L} \mathrm{NaF}$ only increased COL1A1 expression at 7 days. Similar to the ALP activity assessment, $10 \mu \mathrm{mol} / \mathrm{L} \mathrm{NaF}$ increased ALP mRNA level at both 7 and 14 days. However, no significant difference in COL1A1 and ALP mRNA expression with $10 \mu \mathrm{mol} / \mathrm{L} \mathrm{NaF}$ at 21 days was observed. PDLCs at this age might have already finished the conversion phrase, proliferation phase and cell aggregation secretory phase. OCN is a specific maker for late stages of osteoblastic differentiation, implying that at this time the cultured cells would present the phenotype of mature osteoblasts (27). Unlike other genes, the expression of OCN mRNA increased slightly in the $10 \mu \mathrm{mol} / \mathrm{L}$ $\mathrm{NaF}$ groups at 14 and 21 days, but these data had no statistical significance. Similar results were reported in fluoride-treated fibroblast and osteoblast at $48 \mathrm{~h}$ with no statistical significance in expression of OCN mRNA (4).
To further confirm the bone formation induced by fluoride in osteogenic medium, Alizarin red $S$ staining was used to analyze mineralization in PDLCs in vitro. The result shows that $10 \mu \mathrm{mol} / \mathrm{L} \mathrm{NaF}$ lead to an increased activity compared with the control group. In contrast, and to our surprise, both $5 \times 10^{2}$ and $1 \times 10^{3}$ $\mu \mathrm{mol} / \mathrm{L} \mathrm{NaF}$ presented an effect of inhibition on the calcified nodules formation of PDLCs at 28 days, since cells did not reduce the ALP activity. The exact reason for this finding was unclear; however, it might be explained by the different cell passages and the experimental conditions.

In conclusion, the results suggest that moderate concentrations of $\mathrm{NaF}$ can stimulate proliferation and mineralization in PDLCs. This information may provide a novel therapeutic approach for acceleration of periodontal regeneration by addition of a suitable concentration of $\mathrm{NaF}$ into the medication for periodontitis treatment as for instance, into periodontal packs and tissue patches. 


\section{References}

1. Jha SK, Mishra VK, Sharma DK, Damodaran T. Fluoride in the environment and its metabolism in humans. Rev Environ Contam Toxicol 2011; 211: 121-142, doi: 10.1007/9781-4419-8011-3 4.

2. Liu XL, Li CC, Liu KJ, Cui CY, Zhang YZ, Liu Y. The influence of fluoride on the expression of inhibitors of Wnt/ beta-catenin signaling pathway in rat skin fibroblast Cells. Biol Trace Elem Res 2012; 148: 117-121, doi: 10.1007/ s12011-012-9333-9.

3. Beresford JN. Osteogenic stem cells and the stromal system of bone and marrow. Clin Orthop Relat Res 1989; 270-280.

4. Duan X, Xu H, Wang Y, Wang H, Li G, Jing L. Expression of core-binding factor alpha1 and osteocalcin in fluoridetreated fibroblasts and osteoblasts. J Trace Elem Med Biol 2014; 28: 278-283, doi: 10.1016/j.jtemb.2014.02.004.

5. Abbayya K, Zope SA, Naduwinmani S, Pisal A, Puthanakar N. Cell- and gene-based therapeutics for periodontal regeneration. Int J Prev Med 2015; 6: 110, doi: 10.4103/ 2008-7802.169080.

6. Marchesan JT, Scanlon CS, Soehren S, Matsuo M, Kapila YL. Implications of cultured periodontal ligament cells for the clinical and experimental setting: a review. Arch Oral Biol 2011; 56: 933-943, doi: 10.1016/j.archoralbio.2011.03.003.

7. McCulloch CA, Bordin S. Role of fibroblast subpopulations in periodontal physiology and pathology. J Periodontal Res 1991; 26: 144-154., doi: 10.1111/j.1600-0765.1991. tb01638.x.

8. Kook SH, Heo JS, Lee JC. Crucial roles of canonical Runx2dependent pathway on Wnt1-induced osteoblastic differentiation of human periodontal ligament fibroblasts. $\mathrm{Mol}$ Cell Biochem 2015; 402: 213-223, doi: 10.1007/s11010015-2329-y.

9. Li S, Zhang H, Li S, Yang Y, Huo B, Zhang D. Connexin 43 and ERK regulate tension-induced signal transduction in human periodontal ligament fibroblasts. J Orthop Res 2015; 33: 1008-1014, doi: 10.1002/jor.22830.

10. Li DX, Deng TZ, Lv J, Ke J. Advanced glycation end products (AGEs) and their receptor (RAGE) induce apoptosis of periodontal ligament fibroblasts. Braz J Med Biol Res 2014; 47: 1036-1043, doi: 10.1590/1414-431X20143996.

11. Yuan G, Cai C, Dai J, Liu Y, Zhang R, Dai Y, et al. Progesterone modulates the proliferation and differentiation of human periodontal ligament cells. Calcif Tissue Int 2010; 87: 158-167, doi: 10.1007/s00223-010-9377-9.

12. Yamamoto T, Ugawa $Y$, Yamashiro K, Shimoe M, Tomikawa $\mathrm{K}$, Hongo $\mathrm{S}$, et al. Osteogenic differentiation regulated by Rho-kinase in periodontal ligament cells. Differentiation 2014; 88: 33-41, doi: 10.1016/j.diff.2014.09.002.

13. Kawahara $T$, Yamashita $M$, Ikegami $K$, Nakamura $T$, Yanagita M, Yamada S, et al. TGF-beta negatively regulates the BMP2-dependent early commitment of periodontal ligament cells into hard tissue forming cells. PLoS One 2015; 10: e0125590, doi: 10.1371/journal.pone.0125590

14. An S, Huang X, Gao Y, Ling J, Huang Y, Xiao Y. FGF-2 induces the proliferation of human periodontal ligament cells and modulates their osteoblastic phenotype by affecting Runx2 expression in the presence and absence of osteogenic inducers. Int J Mol Med 2015; 36: 705-711, doi: 10.3892/ijmm.2015.2271.

15. Wei $\mathrm{Y}, \mathrm{Wu} \mathrm{Y}$, Zeng $\mathrm{B}$, Zhang $\mathrm{H}$. Effects of sodium fluoride treatment in vitro on cell proliferation, BMP-2 and BMP-3 expression in human osteosarcoma MG-63 cells. Biol Trace Elem Res 2014; 162: 18-25, doi: 10.1007/s12011-014-0148-8.

16. Pan L, Shi X, Liu S, Guo X, Zhao M, Cai R, et al. Fluoride promotes osteoblastic differentiation through canonical Wnt/ beta-catenin signaling pathway. Toxicol Lett 2014; 225: 34-42, doi: 10.1016/j.toxlet.2013.11.029.

17. Li XN, Lv P, Sun Z, Li GS, Xu H. Role of unfolded protein response in affecting osteoblast differentiation induced by fluoride. Biol Trace Elem Res 2014; 158: 113-121, doi: 10.1007/s12011-014-9897-7.

18. Faibish D, Suzuki M, Bartlett JD. Appropriate real-time PCR reference genes for fluoride treatment studies performed in vitro or in vivo. Arch Oral Biol 2016; 62: 33-42, doi: 10.1016/ j.archoralbio.2015.11.004.

19. Zhang C, Li J, Zhang L, Zhou Y, Hou W, Quan H, et al. Effects of mechanical vibration on proliferation and osteogenic differentiation of human periodontal ligament stem cells. Arch Oral Biol 2012; 57: 1395-1407, doi: 10.1016/j. archoralbio.2012.04.010.

20. Basdra EK, Komposch G. Osteoblast-like properties of human periodontal ligament cells: an in vitro analysis. Eur $\mathrm{J}$ Orthod 1997; 19: 615-621., doi: 10.1093/ejo/19.6.615.

21. Lee JH, Jung JY, Jeong YJ, Park JH, Yang KH, Choi NK, et al. Involvement of both mitochondrial- and death receptordependent apoptotic pathways regulated by $\mathrm{Bcl}-2$ family in sodium fluoride-induced apoptosis of the human gingival fibroblasts. Toxicology 2008; 243: 340-347, doi: 10.1016 lj.tox.2007.10.026.

22. Satoh R, Kishino K, Morshed SR, Takayama F, Otsuki S, Suzuki $F$, et al. Changes in fluoride sensitivity during in vitro senescence of normal human oral cells. Anticancer Res 2005; 25: 2085-2090.

23. Guida L, Annunziata M, Rocci A, Contaldo M, Rullo R, Oliva A. Biological response of human bone marrow mesenchymal stem cells to fluoride-modified titanium surfaces. Clin Oral Implants Res 2010; 21: 1234-142, doi: 10.1111/j.16000501.2010.01929.x

24. Komori T. Regulation of bone development and extracellular matrix protein genes by RUNX2. Cell Tissue Res 2010; 339: 189-195, doi: 10.1007/s00441-009-0832-8.

25. Prince M, Banerjee C, Javed A, Green J, Lian JB, Stein GS, et al. Expression and regulation of Runx2/Cbfa1 and osteoblast phenotypic markers during the growth and differentiation of human osteoblasts. I Cell Biochem 2001; 80: 424-440 doi: 10.1002/1097-4644(20010301) 80:3<424::AID-JCB160 > 3.0.CO;2-6.

26. Franceschi RT, Ge C, Xiao G, Roca H, Jiang D. Transcriptional regulation of osteoblasts. Ann N Y Acad Sci 2007; 1116: 196-207, doi: 10.1196/annals.1402.081.

27. Ram VS, Parthiban, Sudhakar U, Mithradas N, Prabhakar R. Bonebiomarkers in periodontal disease: a review article. J Clin Diagn Res 2015; 9: ZE07-ZE10, doi: 10.7860/JCDR/ 2015/11268.5438. 